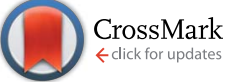

Cite this: J. Mater. Chem. A, 2015, 3, 21099

Received 10th July 2015

Accepted 7th September 2015

DOI: $10.1039 / \mathrm{c} 5 \mathrm{ta} 05226 \mathrm{~b}$

www.rsc.org/MaterialsA

\section{Ammonia-storage in lithium intercalated fullerides $\uparrow$}

\author{
D. Pontiroli, ${ }^{a}$ D. D'Alessio, ${ }^{a}$ M. Gaboardi, ${ }^{a}$ G. Magnani, ${ }^{a}$ C. Milanese, ${ }^{b}$ S. G. Duyker, ${ }^{\text {cd }}$ \\ V. K. Peterson, ${ }^{c}$ N. Sharma ${ }^{e}$ and M. Riccò ${ }^{\star a}$
}

\section{Introduction}

The depletion of oil reserves and the environmental damage caused by burning fossil fuels represent major global issues, which could be overcome by switching to the so-called "Hydrogen economy". ${ }^{1}$ Hydrogen is a very efficient energy vector, able to deliver three times the energy of other chemical fuels and burns without emitting greenhouse gases. ${ }^{2}$ However, one of the main problems with hydrogen is the development of an efficient hydrogen-storage system, especially for automotive applications. Among the solutions proposed, the best performance is reached by loading hydrogen in solid-state materials, but so far none of these are able to meet the technical targets imposed by industry and the Department of Energy (US DoE). ${ }^{3}$

In this context, the feasibility to use ammonia as a hydrogen carrier represents an interesting alternative, since ammonia is easy to synthesize and allows high $\mathrm{H}_{2}$ storage capacity (up to 18 wt\% in liquid $\left.\mathrm{NH}_{3}\right) .{ }^{4}$ Currently, ammonia is mainly produced by reacting atmospheric nitrogen with the hydrogen contained in natural gas, through the Haber process; ${ }^{5}$ but other sources, such as coal or coke gasification, are available, which, in combination with $\mathrm{CO}_{2}$ sequestration, could in principle offer a

${ }^{a}$ Dipartimento di Fisica e Scienze della Terra, Università di Parma, Viale delle Scienze 7/a, 43124 Parma, Italy. E-mail: mauro.ricco@fis.unipr.it

${ }^{b}$ Pavia $\mathrm{H}_{2}$ Lab, C.S.G.I \& Dipartimento di Chimica, Sezione di Chimica Fisica, Università degli Studi di Pavia, V.le Taramelli 16, 27100 Pavia, Italy

${ }^{c}$ The Bragg Institute, Australian Nuclear Science and Technology Organisation, Locked Bag 2001, Kirrawee DC, NSW 2232, Australia

${ }^{d}$ School of Chemistry, The University of Sydney, Sydney, Australia ${ }^{e}$ School of Chemistry, University of New South Wales (UNSW), Sydney, Australia

$\dagger$ Electronic supplementary information (ESI) available. See DOI: $10.1039 / \mathrm{c} 5 \mathrm{ta} 05226 \mathrm{~b}$ long-term ammonia production at zero emission. ${ }^{4}$ In contrast to hydrogen, even though liquid $\mathrm{NH}_{3}$ is more toxic than common hydrocarbons, infrastructure for handling and transporting bulk ammonia are already well-established and developed. Nevertheless, especially for mobile applications, hazards associated with ammonia use should be further reduced ideally being a safer solution than gasoline. These hazards can in principle be lowered by storing ammonia in solid systems, such as metal ammines, which are able to reversibly absorb/desorb ammonia gas, provided at elevated temperatures. ${ }^{6}$ Use of $\mathrm{NH}_{3}$ as a fuel can be direct, for instance by feeding ammonia straight into solid oxide fuel cells (SOFC), ${ }^{7}$ or indirect, through the catalytic decomposition of ammonia ${ }^{8}$ at high temperatures $\left(300-500{ }^{\circ} \mathrm{C}\right)$ and using hydrogen as an energy source.

Notably, some common solid ammonia containing systems find direct use as hydrogen-storage materials, for example, ammonia borane $\left(\mathrm{NH}_{3} \mathrm{BH}_{3}\right.$ with $\left.19.6 \mathrm{wt} \% \mathrm{H}_{2}\right),{ }^{9}$ or the ammonia complexes of borohydrides $\left(\mathrm{LiBH}_{4} \cdot n \mathrm{NH}_{3}\right.$ with $18 \mathrm{wt} \% \mathrm{H}_{2}$, $\mathrm{Mg}\left(\mathrm{BH}_{4}\right)_{2} \cdot n \mathrm{NH}_{3}$ with $\left.16 \mathrm{wt} \% \mathrm{H}_{2}\right){ }^{10,11}$ This is because in these compounds the thermal decomposition usually causes the recombination of the $\mathrm{N}-\mathrm{H}$ and $\mathrm{B}-\mathrm{H}$ groups (followed by $\mathrm{H}_{2}$ emission), rather than the release of pure ammonia. It is worth noting that this recombination makes the $\mathrm{H}_{2}$-storage irreversible in these systems. The situation is different in the case of metal ammine complexes $\mathrm{M}\left(\mathrm{NH}_{3}\right)_{n} \mathrm{X}_{m}$, where $\mathrm{M}$ is a metal cation (e.g. $\mathrm{Mg}, \mathrm{Ca}, \mathrm{Ni})$ and $\mathrm{X}$ is an anion (e.g. $\left.\mathrm{Cl}, \mathrm{SO}_{4}\right)$. Metal ammine complexes ${ }^{6,12}$ were reported to reversibly store up to $10 \mathrm{wt} \% \mathrm{NH}_{3}$, although the complete ammonia release occurs at temperatures too high for practical applications, i.e. up to $650 \mathrm{~K}$. More recently, the complex $\mathrm{Li}_{2} \mathrm{~B}_{12} \mathrm{H}_{12}$ was found to catch seven $\mathrm{NH}_{3}$ molecules and to completely release them below $473 \mathrm{~K}$, corresponding to $43.4 \mathrm{wt} \% \mathrm{NH}_{3}$ stored under mild 
conditions. ${ }^{13}$ Another noteworthy compound is $\mathrm{LiBH}_{4}$, forming four stable ammoniated species. ${ }^{14}$ In particular, the monoammoniated phase of lithium borohydride contains $44 \mathrm{wt} \%$ ammonia and was reported to release ammonia at the accessible thermal decomposition temperature of just $313 \mathrm{~K}$, although it presents a minor equilibrium $\mathrm{NH}_{3}$ vapour pressure (8.4 mbar) at room temperature. ${ }^{15}$ Different approaches, based on the $\mathrm{NH}_{3}$ physisorption in highly porous materials, like covalent organic frameworks (COFs), led to lower storage performance, up to $25.5 \mathrm{wt} \%$ ammonia stored at 1 bar. $^{16}$

Recently, alkali intercalated fullerides (AIFs) have attracted some interest in the field of solid energy storage, for their ability to reversibly absorb hydrogen with favourable binding energies. ${ }^{17-19}$ In the case of hydrogen, the storage mechanism occurs through the chemical bond of $\mathrm{H}$ atoms on the $\mathrm{C}_{60}$ molecule (formation of the hydrofullerene $\mathrm{C}_{60} \mathrm{H}_{x}$ ), which is mediated ${ }^{20}$ by the catalytic activity of the intercalated alkali (lithium, sodium) clusters ${ }^{21-24}$ and can be optimized by the presence of catalysers. ${ }^{25,26}$

The ability of AIFs to react with ammonia is another wellknown phenomenon. ${ }^{27,28}$ Typically, $\mathrm{NH}_{3}$ molecules can be cointercalated in the AIF lattice interstices directly during the synthesis stage, from the reaction of $\mathrm{C}_{60}$ with the alkali metal (e.g. $\mathrm{Li}, \mathrm{Na}, \mathrm{K}$ ) in ammonia solution, ${ }^{29}$ or by exposing the prepared AIF to ammonia vapours. ${ }^{30}$ Ammonia acts as a neutral spacer for the fulleride lattice and coordinates with the alkali ions. ${ }^{31,32}$ The induced lattice expansion dramatically affects the electronic and magnetic properties of the metallic highlycorrelated AIF phases, which generally lie on the verge of a metal-to-insulator transition. ${ }^{33}$ However, despite the intense research activity on these compounds, so far there have been no investigations on these systems for ammonia-storage purposes.

In this work, the $\mathrm{ND}_{3}$ desorption as a function of the temperature of the ammoniated phases of lithium fulleride $\left(\mathrm{ND}_{3}\right)_{y} \mathrm{Li}_{6} \mathrm{C}_{60}$ is investigated using neutron powder diffraction (NPD). The structural evolution of the compound was, in addition to the NPD data, followed by the in-situ monitoring of ammonia release via a Sievert apparatus directly connected to the sample-holder. Ex-situ manometric measurements and differential scanning calorimetry (DSC) analyses were also performed, in order to precisely determine the thermodynamic properties of this system.

\section{Experimental}

\section{Synthesis}

The hyper-ammoniated lithium fullerides $\left(\mathrm{ND}_{3}\right)_{y} \mathrm{Li}_{x} \mathrm{C}_{60}$, with $x$ $=3,6$, and 12 , were prepared as follows. First, approximately half-gram of $\mathrm{Li}_{x} \mathrm{C}_{60}$ was synthesized by mixing stoichiometric amounts of finely cut metallic Li (Aldrich, $99.9 \%$ purity) and $\mathrm{C}_{60}$ powder (MER corp., 99.9\% purity) via high-energy ball-milling. Specifically, the reagents were put in a $10 \mathrm{~mL}$ agate bowl of a mini-mill Fritsch Pulverisette 23 with three agate grinding-balls and were milled for $30 \mathrm{~min}$ at $30 \mathrm{~Hz}$ in an Ar atmosphere $(<0.1$ ppm $\mathrm{H}_{2} \mathrm{O}, \mathrm{O}_{2}$ ). After this step, a homogeneous black powder was obtained, which was placed in a Pyrex Schlenk vial under vacuum in thermal contact with a methanol bath at $213 \mathrm{~K}$ and anhydrous deuterated ammonia (ISOTEC INC $_{\text {, }}$ min 99 atom\% D) was slowly condensed on the sample. The temperature was then increased to $243 \mathrm{~K}$ and the mixture was kept overnight under continuous magnetic stirring. Following this reaction, excess ammonia in the reactor was slowly condensed back into a bottle dipped in liquid $\mathrm{N}_{2}$, finely regulating the evaporation with a needle valve and progressively increasing the temperature from 243 to $273 \mathrm{~K}$. After the complete evaporation of $\mathrm{ND}_{3}$ gas, the reactor containing the ammoniated sample was sealed and quickly put in an Ar glove box and the product was recovered from the vial.

\section{Methods}

Preliminary X-ray powder diffraction (XPD) measurements were performed with a Bruker D8 Discover diffractometer, operating in Debye-Scherrer geometry, equipped with a $\mathrm{CuK}_{\alpha}$ sealed tube generator and a 2D area (GADDS) detector.

NPD experiments were performed on the three obtained hyper-ammoniated lithium fullerides $\left(\mathrm{ND}_{3}\right)_{y} \mathrm{Li}_{x} \mathrm{C}_{60}$ at the highflux powder diffractometer WOMBAT ${ }^{34}$ at the Bragg Institute of the Australian Nuclear Science and Technology Organisation (ANSTO, Sydney, Australia), using an incident wavelength of $\lambda=$ 2.9654(2) $\AA$, determined using the $\mathrm{La}^{11} \mathrm{~B}_{6}$ NIST standard reference material $660 \mathrm{~b}$. The high neutron flux intensity on this instrument meant that the typical accumulation time of each pattern was on the order of $1 \mathrm{~min}$. Samples were loaded in vanadium cells equipped with a gas delivery tube and isolation valve. Sample loading was performed in a He glove-box with $<0.1 \mathrm{ppm}_{2} \mathrm{O}$ and $\mathrm{O}_{2}$. The gas delivery tube was then connected with a Hiden Isochema IMI gas-delivery system, able to perform in-situ Sievert analysis of the $\mathrm{ND}_{3}$ desorption process. During the experiment, $\mathrm{ND}_{3}$ desorption was induced by gradually increasing the temperature of samples, which was varied in the range of $15-500 \mathrm{~K}$ using a cryofurnace on the sample position. The temperature was controlled via a k-type thermocouple at the base of the sample cell, with a second thermocouple attached to the cell above the sample level for monitoring purposes.

Samples synthesized at the same conditions starting from natural ammonia (Aldrich, 99.99+\% purity) were investigated in parallel with $e x$-situ manometric/DSC analysis at the Pavia $\mathrm{H}_{2}$ lab, by heating the sample from room temperature up to $653 \mathrm{~K}$ under $0.3 \mathrm{bar}$ of $\mathrm{He}$ at $5 \mathrm{~K} \mathrm{~min}^{-1}$ in a high pressure cell of a Sensys DSC (Setaram) connected with a PCTPro-2000 manometric instrument (Hy Energy-Setaram). This was undertaken in order to better determine the thermodynamic parameters of the $\mathrm{NH}_{3}$ release process.

\section{Results and discussion}

Preliminary XPD data collected either on the Li-only intercalated fulleride precursors, or on the hyper-ammoniated $\left(\mathrm{ND}_{3}\right)$ ${ }_{y} \mathrm{Li}_{x} \mathrm{C}_{60}$ samples, revealed strong differences among them (see ESI, Fig. 1S $\dagger$ ). The former shows the expected fcc pattern profile, ${ }^{25}$ with the absence of unreacted $\mathrm{C}_{60}$ or $\mathrm{Li}$. On the other hand, in the latter the shift of the reflection to lower $2 \theta$ values is 
indicative of the effective co-intercalation of the ammonia molecules in the host fulleride lattice. In order to quantify the $\mathrm{ND}_{3}$ concentration in the samples, the weights were compared before and after the ammoniation process. In the case of $x=6$ the nominal stoichiometry was found to be $\left(\mathrm{ND}_{3}\right)_{13,99(15)} \mathrm{Li}_{6} \mathrm{C}_{60}$, corresponding to $36.8(3) \mathrm{wt} \% \mathrm{ND}_{3}$ absorbed by the sample.

\section{Structural thermal evolution}

In Fig. 1 right, a colour map showing the evolution of the neutron powder diffraction patterns for the $\left(\mathrm{ND}_{3}\right)_{y} \mathrm{Li}_{6} \mathrm{C}_{60}$ sample is displayed as a function of temperature. It is possible to identify at least four distinctive regions, corresponding to the three different structural phase transitions, that the Li intercalated fulleride experiences when different amounts of $\mathrm{ND}_{3}$ are co-intercalated in the sample. In Fig. 1 left, the thermal evolution of the normalized total counts (i.e. the neutron total counts measured by the detectors, normalized to the incident neutron flux) is shown (red curve), which is approximately proportional to the mass of the sample and follows well the structural evolution. Concomitant with the phase transitions, a decrease of the mass of the sample is noted and this is ascribed to the ammonia release. The normalized total counts are plotted together with the effective $\mathrm{ND}_{3}$ stoichiometry of the sample (black curve), monitored by in-situ manometric measurements, performed by continuously monitoring the pressure of a reference vessel. This forms a closed system with the sample vessel and was monitored during the whole desorption process. In order to keep the ammonia pressure on the sample roughly constant and to avoid perturbations of the desorption process itself, the manifold was manually evacuated when the pressure overcame the value of 1 bar (after isolating the sample vessel). Hence, the black curve shown in Fig. 1 was obtained by measuring the cumulative pressure during the desorption process, discarding the evacuation stages. This value is approximately proportional to the amount of ammonia released and resulted in a value of around 14 ammonia molecules per formula unit absorbed in the hyper-ammoniated phase, which is in good agreement with the weighted value.

For the sake of clarity, selected diffraction patterns of the four regions are plotted in separate panels displayed in Fig. 2. Below room temperature, the diffraction pattern consists of a set of broad peaks, superimposed to few narrower ones. Although not indexed, the broad peaks were ascribed to the
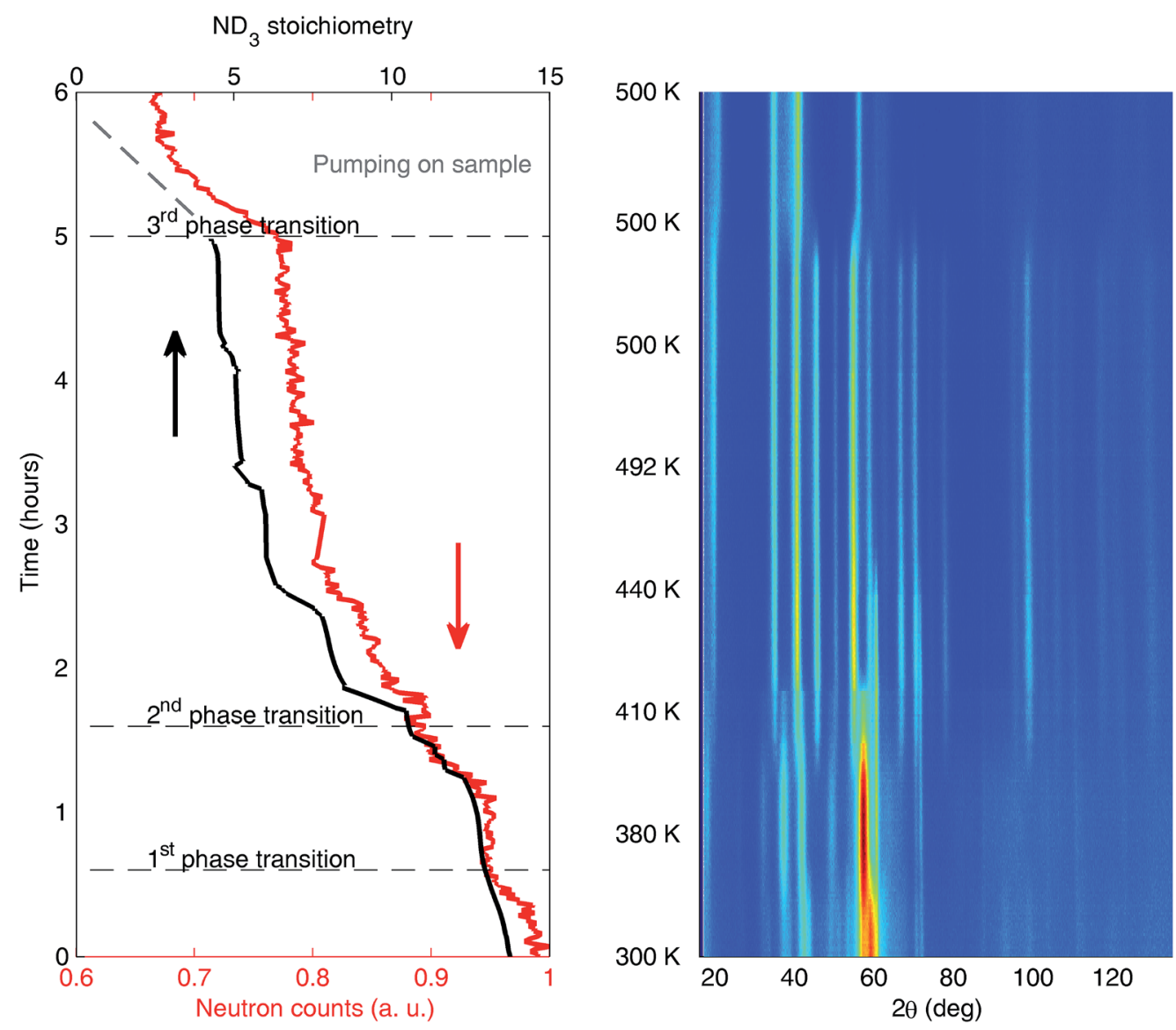

Fig. 1 Left: Time evolution of the normalized total counts (red) of $\left(\mathrm{ND}_{3}\right)_{y} \mathrm{Li}_{6} \mathrm{C}_{60}$, plotted together with the estimated $\mathrm{ND}_{3}$ stoichiometry of the sample (black), as evaluated by in-situ Sievert analysis. Right: Colour map showing the thermal evolution of the neutron diffraction profile in the range 300-500 K. The presence of three structural phase transitions at $350 \mathrm{~K}, 410 \mathrm{~K}$ and $500 \mathrm{~K}$ is evident. These are promoted by the progressive desorption of $\mathrm{ND}_{3}$ molecules, co-intercalated in the host fullerene lattice. Discrete temperature points are reported in the middle, referring both to the left and right plots. 

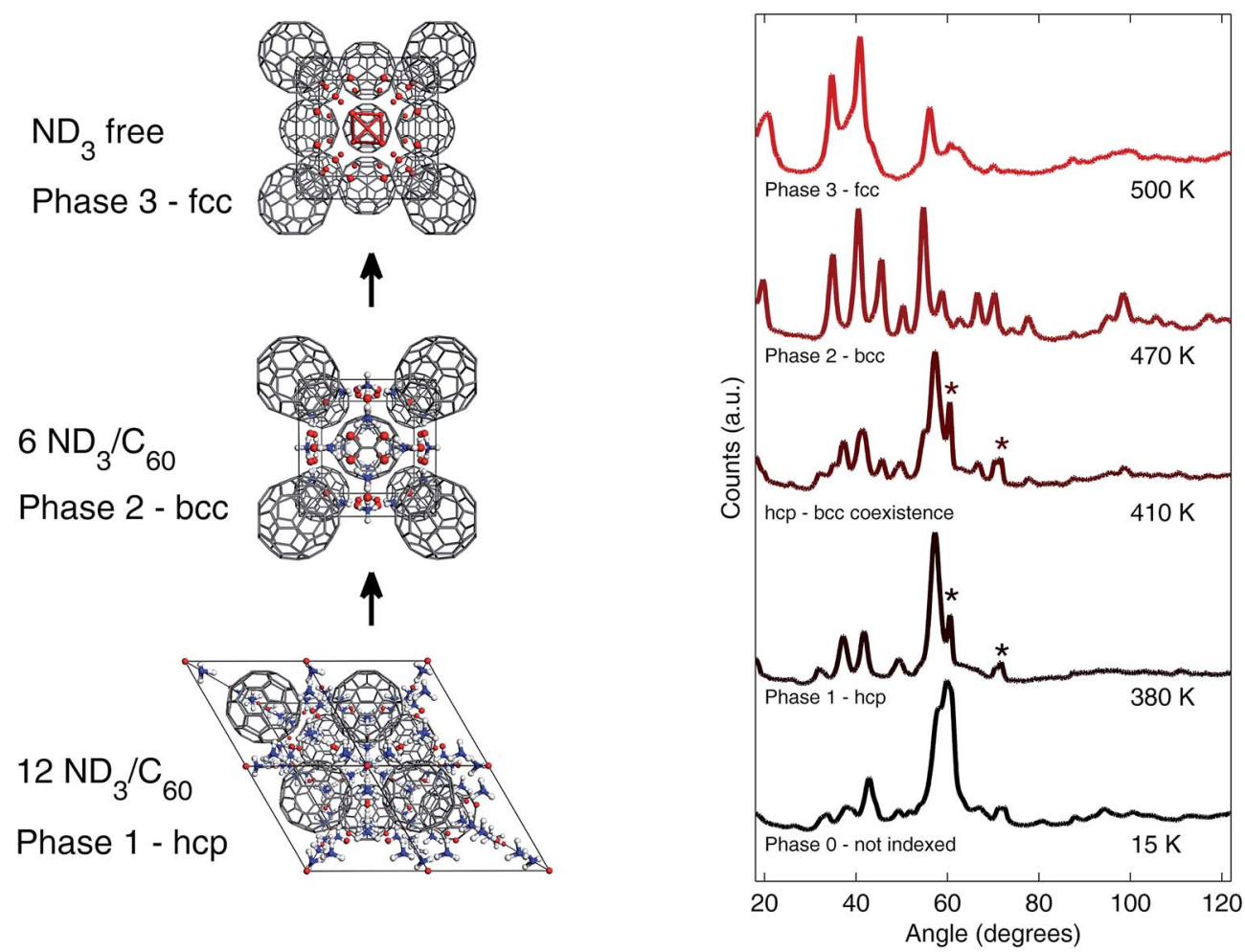

Fig. 2 Left: Structural representation for the three indexed phases of $\mathrm{Li}_{6} \mathrm{C}_{60}$ at different degrees of ammoniation. Right: Selected powder neutron diffraction patterns of the $\left(\mathrm{ND}_{3}\right)_{y} \mathrm{Li}_{6} \mathrm{C}_{60}$ sample during the $\mathrm{ND}_{3}$ desorption process, referring to the four identified phases discussed in the text. Some sharp peaks (indicated by asterisks) were ascribed to the spurious $\mathrm{LiND}_{2}$ phase, which in this sample is present in a very low amount (<2 wt\%), thus not significantly affecting the sample properties.

hyper-expanded ammoniated fulleride phase containing up to 14 ammonia molecules per $\mathrm{C}_{60}$ (phase 0 ), while the latter were indexed to the tetragonal phase of $\mathrm{LiND}_{2}$ (S.G. I4, $a=b=5.03(1)$ $\AA, c=10.26(3) \AA)^{35}$ which is present as the minority phase in the sample $(<2 \mathrm{wt} \%)$.

At around $350 \mathrm{~K}$, the first phase transition occurs, indicated by a slight rearrangement of the fulleride cell parameters, which is probably associated with a small amount of ammonia released by the sample. The reflections were successfully indexed to a hexagonal cell, containing about $12 \mathrm{ND}_{3}$ molecules per $\mathrm{C}_{60}$ (phase 1-hcp, $a=10.86(1) \AA, c=18.57(1) \AA, \gamma=120^{\circ}$, $\left.V_{\text {cell }}=1794(5) \AA^{3}-V_{\mathrm{C}_{60}}=948(2) \AA^{3}\right)$.

A more dramatic structural transition is found at $410 \mathrm{~K}$, when the powder pattern starts to change, with new peaks arising in the region at $30<2 \theta<50^{\circ}$. At the same time, the total counts rapidly decrease, indicating a significant loss of the sample mass. At $470 \mathrm{~K}$ this second phase transition is complete and all the observed reflections are indexed to a bcc phase, isostructural to the already known Mott-Hubbard insulating phase of $\left(\mathrm{NH}_{3}\right)_{6} \mathrm{Li}_{3} \mathrm{C}_{60}$ (phase 2-bcc, S.G. $\operatorname{Im} \overline{3}, a=11.92(1) \AA, V_{\text {cell }}$ $\left.=1742(6) \AA^{3}-V_{\mathrm{C}_{60}}=871(3) \AA^{3}\right) .^{29,32}$

It is worth noting that at this stage (above $470 \mathrm{~K}$ ) the peaks referred to $\mathrm{LiND}_{2}$ are no longer present, even if the melting point and the decomposition temperature of the $\mathrm{LiND}_{2}$ phase are expected at a much higher temperatures (648 and $973 \mathrm{~K}$ respectively). This fact, which was not observed in the other investigated samples (see ESI, Fig. $2 \mathrm{~S} \dagger$ ), could be due to a chemical reaction occurring between the segregated $\mathrm{Li}$ amide and the fulleride, similarly to what observed in case of hydrides. ${ }^{18}$

The bcc phase appears stable for a wide range of temperatures, against a continuous loss of mass probed by the neutron total counts; during this stage the estimated amount of ammonia ranges between 7 and $5 \mathrm{ND}_{3}$ molecules per $\mathrm{C}_{60}$.

Finally, at $500 \mathrm{~K}$ a third structural phase transition is observed, which suddenly brings to a fcc rearrangement of the fullerene packing, similarly to what is observed in pristine $\mathrm{Li}_{6} \mathrm{C}_{60}$ (phase 3-fcc, S.G. $F m \overline{3} m, a=14.02(1) \AA, V_{\text {cell }}=2758(5) \AA^{3}$ $\left.-V_{\mathrm{C}_{60}}=689(3) \AA^{3}\right) .{ }^{17,25}$ This phase is compatible with an ammonia-free structure. The comparison between the mass before and after the experiment, in fact, reveals a loss of about $26.7 \mathrm{wt} \%$, which corresponds to the complete desorption of ammonia from the sample. A more precise determination of the parameters describing the ammonia release process is discussed below, through the analysis of manometric/DSC data collected ex-situ (see also Table 1).

Similar neutron powder diffraction measurements were performed on $\left(\mathrm{ND}_{3}\right)_{y} \mathrm{Li}_{x} \mathrm{C}_{60}$ samples with $x=3$ and 12 and data were shown in Fig. $2 \mathrm{~S}$ of the ESI. $\dagger$ However, in these cases the ammonia-storage performance was revealed to be worse if compared with $\mathrm{Li}_{6} \mathrm{C}_{60}$. In particular, for $\left(\mathrm{ND}_{3}\right)_{y} \mathrm{Li}_{3} \mathrm{C}_{60}$, the amount of co-intercalated ammonia turned out to be significantly lower, on the order of $10 \mathrm{wt} \%$. This is most likely due to the lack of formation of a hyper-expanded ammoniated phase 
Table 1 Crystal symmetry, $\mathrm{ND}_{3}$ content and transition temperature, detected either with in-situ or ex-situ manometric measurements, for the four phases assumed by $\left(\mathrm{ND}_{3}\right)_{y} \mathrm{Li}_{6} \mathrm{C}_{60}$ on heating

\begin{tabular}{|c|c|c|c|c|}
\hline Phase & Symmetry & $\begin{array}{l}\mathrm{ND}_{3} \text { cont. } \\
\text { (wt } \%)\end{array}$ & $\begin{array}{l}\text { In-situ } \\
\text { tr. } T(\mathrm{~K})\end{array}$ & $\begin{array}{l}E x \text {-situ tr. } \\
T(\mathrm{~K})\end{array}$ \\
\hline Phase 0 & Not indexed & $36.8(3)$ & - & - \\
\hline Phase 1 & hcp & $\sim 32$ & $\sim 350 \mathrm{~K}$ & - \\
\hline Phase 2 & bcc & $13-18$ & $\sim 410 \mathrm{~K}$ & $350(5) \mathrm{K}$ \\
\hline Phase 3 & fcc & - & $\sim 500 \mathrm{~K}$ & $535(5) \mathrm{K}$ \\
\hline
\end{tabular}

in this case. Moreover, the complete desorption of ammonia was not reached during the in-situ thermal treatment - even at $500 \mathrm{~K}$ the sample still shows the bcc arrangement.

On the other hand, in the case of $\left(\mathrm{ND}_{3}\right)_{y} \mathrm{Li}_{12} \mathrm{C}_{60}$ the behaviour is similar to $\left(\mathrm{ND}_{3}\right)_{y} \mathrm{Li}_{6} \mathrm{C}_{60}$, even if a rather large amount of $\mathrm{LiND}_{2}$ is present. The increase in the $\mathrm{LiND}_{2}$ content at this composition is due to the partial reaction of $\mathrm{Li}$ with $\mathrm{ND}_{3}$ during the ammoniation process. The peaks ascribed to $\mathrm{LiND}_{2}$ remain during the whole thermal treatment (see Fig. $2 \mathrm{~S} \dagger$ ) and allowed us to estimate the amide amount in the sample at about $12 \mathrm{wt} \%$. Such an amount clearly affects the effective stoichiometry of the $\mathrm{Li}$ fulleride, which after corrections, turns out to be $\mathrm{Li}_{6.7(5)} \mathrm{C}_{60}$, where part of the $\mathrm{Li}$ is involved in the formation of the amide phase. Notably, this fact also suggests an upper limit for the Li stoichiometry of the ammoniated $\left(\mathrm{ND}_{3}\right)_{y} \mathrm{Li}_{x} \mathrm{C}_{60}$ phases, with $x$ around 6 .

\section{Ex-situ $\mathrm{NH}_{3}$ desorption}

Desorption of ammonia in $\left(\mathrm{NH}_{3}\right)_{y} \mathrm{Li}_{6} \mathrm{C}_{60}$ was also monitored with ex-situ manometric/DSC coupled measurements, in order to further understand the discharge process. In Fig. 3a, the evolution of the amount of ammonia desorbed from the sample is shown as a function of temperature, in the range 300-650 K. Temperature was increased at a rate of $5 \mathrm{~K} \mathrm{~min}^{-1}$ and the pressure in the sample chamber was kept constant at 0.3 bar, by means of a gas-flow controller. Two steps of mass loss, at around $350 \mathrm{~K}$ and $535 \mathrm{~K}$, respectively, are visible and correspond to the two structural hcp-bcc and bcc-fcc phase transitions discussed above.

The observed transition temperatures are slightly different with respect to those observed in the in-situ NPD experiment, but such discrepancy can be easily rationalized by taking into account the different sample environment, which in this case allowed a more precise control of the thermodynamic parameters. The amount of ammonia released in the two processes is roughly the same and corresponds to about six $\mathrm{NH}_{3}$ molecules per $\mathrm{C}_{60}$. Therefore, these findings confirm the results of the insitu manometric analysis. DCS data indicate that the two desorption processes are endothermic, as expected.

The peak at $350 \mathrm{~K}$ appears broader than the one at $535 \mathrm{~K}$, probably due to the more complex release mechanism of the first process, which actually involves two structural phase transitions (from phase 0 to phase 1 and from phase 1 to phase 2). From the peak area an estimate of the binding-energy of the a)

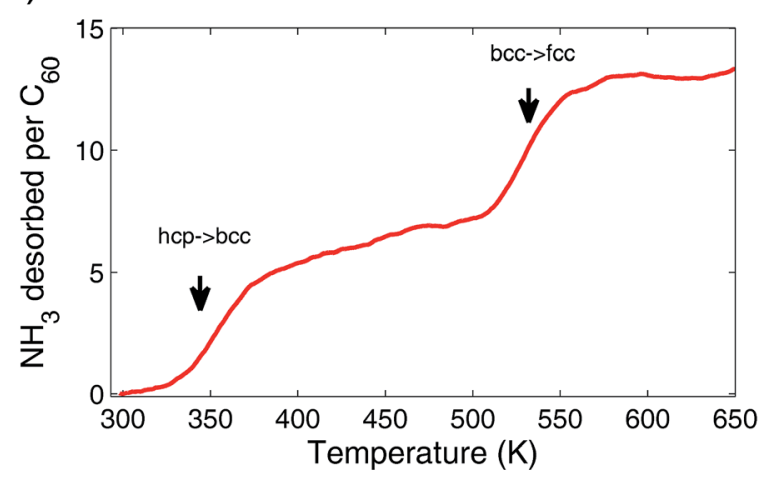

b)

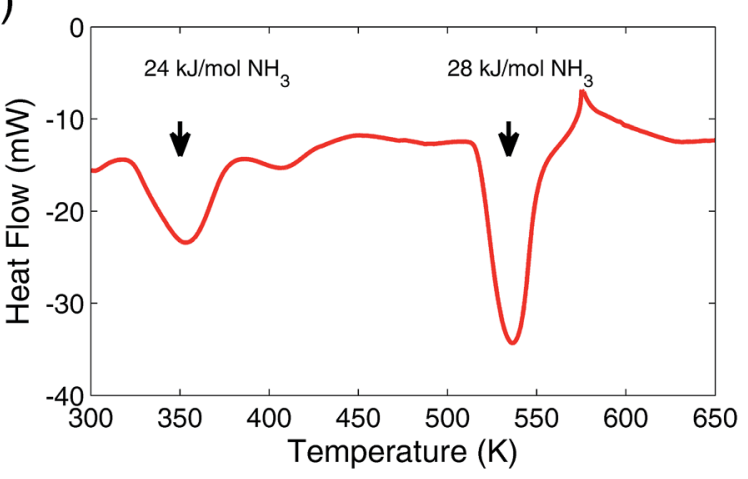

c)

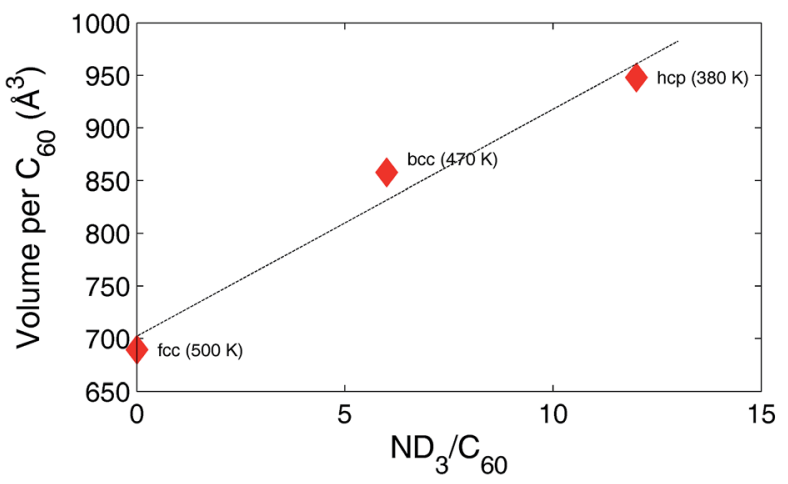

Fig. 3 (a) Manometric data of the $\mathrm{NH}_{3}$ desorption process in $\left(\mathrm{NH}_{3}\right)_{y}-$ $\mathrm{Li}_{6} \mathrm{C}_{60}$ upon heating in the range $300-650 \mathrm{~K}$ (rate of $5 \mathrm{~K} \mathrm{~min}^{-1}$ ). (b) DSC data of the $\mathrm{NH}_{3}$ desorption process. (c) Refined volume per $\mathrm{C}_{60}$ as a function of the number of ammonia molecules intercalated for the ammonia free-, super-expanded bcc- and hyper-expanded hcp phases of $\left(\mathrm{NH}_{3}\right)_{y} \mathrm{Li}_{6} \mathrm{C}_{60}$. The observed trend is roughly linear (dotted line).

released ammonia molecules was calculated. This ranges between 24 and $28 \mathrm{~kJ} \mathrm{~mol}^{-1} \mathrm{NH}_{3}$, a value significantly lower than the binding energy of $\mathrm{Li}-\mathrm{NH}_{3}$ clusters reported in the literature (see also discussion below) ${ }^{36}$

\section{Discussion}

It is well known that the ammonia molecule has the ability to co-intercalate into AIFs and to act as a neutral spacer for the host fullerene lattice. This phenomenon was exploited in the past in order to tune the electronic properties of fullerides. In 
fact, cubic $\mathrm{A}_{3} \mathrm{C}_{60}$ compounds are highly correlated metals, which are found close to a Mott-insulating transition (MIT); a slight increase of the lattice parameter, obtained by inserting ammonia molecules in such compounds, can hence profoundly affect their electronic behaviour, for example pushing-up the superconducting transition temperature of the metallic phase, or even driving the system towards a MIT. ${ }^{37-39}$ However, to our knowledge, no research has so far explored systematically the ammonia-storage properties of these systems.

In particular, the lithium intercalated fulleride $\left(\mathrm{NH}_{3}\right)_{6} \mathrm{Li}_{3} \mathrm{C}_{60}$ is known to be stable under ambient conditions and possesses a super-expanded insulating bcc lattice, which leads to the onball localization of the three electrons donated by $\mathrm{Li}$ to $\mathrm{C}_{60} \cdot{ }^{32} \mathrm{In}$ such a system, two ammonia molecules are coordinated to each Li (see Fig. 2 left) and occupy the $24 \mathrm{~g}$ Wyckoff positions with half fractional occupancy. On the other hand, Li ions are in quasi-linear coordination with these sites, occupying at $25 \%$ occupancy the $24 \mathrm{~g}$ position $(0.38,0.41,0)$, with the $\mathrm{Li}-\mathrm{N}$ distance of $\sim 2.15 \AA$, falling in the typical range observed in $\mathrm{Li}-$ $\mathrm{NH}_{3}$ clusters. ${ }^{29,39,40}$ Such an arrangement indicates a relatively high degree of disorder, suggesting that more Li could in principle be accommodated in the lattice. In fact, in this work we observe a similar bcc structure in the $\left(\mathrm{ND}_{3}\right)_{y} \mathrm{Li}_{6} \mathrm{C}_{60}$ phase, with $y=5-7$ (phase 2), as shown in Fig. 2. This system revealed to be stable in the temperature range 400-500 $\mathrm{K}$ during the desorption experiment and retains about half of the total amount of ammonia that can be stored in this system.

The hyper-expanded $\left(\mathrm{ND}_{3}\right)_{y} \mathrm{Li}_{6} \mathrm{C}_{60}$ (see Fig. 3c), with $y=12$, 14 (phases 0 and 1), shows a different structure, that to our knowledge has been never observed so far, and it is stable up to 350-400 K. Although a detailed structural analysis was not possible, due to the low crystallinity of this phase, for $y=12$ we managed to index all the observed reflections to a hcp cell (see Fig. 2 left and Fig. 1S $\dagger$ ). The hcp-bcc transformation observed during the desorption process, when about half of the ammonia is released through an endothermic process, is not easily explained in terms of group-subgroup relationships, while it can be rationalized in the framework of the Burgers model. ${ }^{\mathbf{1 1}}$ Moreover, the hcp-bcc phase coexistence observed around 410 $\mathrm{K}$ suggests that this is a $1^{\text {st }}$ order phase transition.

Above $500 \mathrm{~K}$, the bcc structure undergoes a further phase transition to cubic fcc (phase 3), which results as an ammoniafree phase (see Fig. 2 and $1 S^{\dagger}$ ). During the NPD experiment, this transition was reached by evacuating the sample space; for this reason, the manometric/DSC measurements provided a slightly higher bcc-fcc transition temperature, of about $535 \mathrm{~K}$.

It is worth noting here that this value is still far lower than the decomposition temperature reported by Durand and coworkers for $\left(\mathrm{NH}_{3}\right)_{6} \mathrm{Li}_{3} \mathrm{C}_{60},{ }^{29}$ which appeared stable up to $673 \mathrm{~K}$. A higher thermal stability for $\left(\mathrm{ND}_{3}\right)_{y} \mathrm{Li}_{3} \mathrm{C}_{60}$ was also evidenced by our NPD data, as for this phase the complete ammonia release was not reached under the accessible thermodynamic conditions (see in Fig. 2S $\dagger$ ). This suggests that the $\mathrm{Li}-\mathrm{NH}_{3}$ binding energy in these systems should be somewhat driven by the $\mathrm{Li}$ stoichiometry, as it is known that, on increasing the Li content, its ionization progressively decreases and, as an example, in $\mathrm{Li}_{12} \mathrm{C}_{60}$ the charge transferred to $\mathrm{C}_{60}$ is of only 6 electrons. ${ }^{22}$
Specifically, over the past years, the stability of the $\mathrm{Li}\left(\mathrm{NH}_{3}\right)_{n}(n=$ 1-5) complexes was thoroughly investigated ${ }^{\mathbf{4 2 - 4 4}}$ in order to understand the unusual optical properties of alkali metals solvated in liquid ammonia; ${ }^{45}$ in particular, the $\mathrm{Li}-\mathrm{N}$ dissociation energies seem to strongly depend either on the number of ammonia molecules coordinated to the alkali atom, or to the charge state of the $\mathrm{Li}\left(\mathrm{NH}_{3}\right)_{n}$ cluster. ${ }^{36}$ In our systems, depending on the amount of co-intercalated ammonia molecules, we expect the formation of $\mathrm{Li}\left(\mathrm{NH}_{3}\right)_{n}$ clusters with $n=1-2$, for which the calculated dissociation enthalpy range between 61.4 $\mathrm{kJ} \mathrm{mol}^{-1}(n=1)$ and $46.1 \mathrm{~kJ} \mathrm{~mol}^{-1}(n=2)$ for the cluster in the neutral state, and between $169 \mathrm{~kJ} \mathrm{~mol}^{-1}(n=1)$ and $125.8 \mathrm{~kJ}$ $\mathrm{mol}^{-1}(n=2)$ for the cations $\mathrm{Li}\left(\mathrm{NH}_{3}\right)_{n}{ }^{+} \cdot{ }^{36}$ Although a direct comparison with these data is not trivial, the DSC data collected on $\left(\mathrm{NH}_{3}\right)_{y} \mathrm{Li}_{6} \mathrm{C}_{60}$ (see Fig. 3b) suggest that the co-intercalation of the Li-ammonia clusters in the fullerene matrix is effective in bringing the $\mathrm{Li}-\mathrm{NH}_{3}$ binding energies towards lower values, probably due to the partial negative charge redistribution on the $\mathrm{C}_{60}$ LUMO.

In order to check the reversibility of the ammoniation process, the completely discharged $\mathrm{Li}_{6} \mathrm{C}_{60}$ sample underwent a second treatment in liquid $\mathrm{NH}_{3}$, under the same conditions employed for the first process. By comparing the weight of the sample before and after the process, an increase of $14.8 \mathrm{wt} \%$ was again found and this corresponds to the nominal stoichiometry $\left(\mathrm{NH}_{3}\right)_{6.64} \mathrm{Li}_{6} \mathrm{C}_{60}$. Therefore, the ammonia-storage appears partially reversible in this system. Laboratory XPD data indicated an improvement of the crystallinity in the ammoniated phase after the second treatment, although a fraction of $\mathrm{Li}$ amide (peak at $2 \theta=43^{\circ}$ in Fig. $\left.1 \mathrm{~S} \dagger\right)^{46}$ also appears. This fact may be due to a partial Li segregation, as a metal, upon the $\mathrm{NH}_{3}$ discharge, followed by the reaction of the bare alkali with ammonia during the second uptake. This process is expected to limit the reversibility of the ammonia absorption of this system. Further investigations are however required in order to better evaluate the robustness of this system upon cycling.

\section{Conclusions}

The known ability of Li fullerides to co-intercalate ammonia was investigated thoroughly, with the aim to evaluate their possible applications in the field of energy-storage. $\mathrm{Li}_{6} \mathrm{C}_{60}$ is found to absorb up to 14 ammonia molecules per $\mathrm{C}_{60}$, corresponding to the notable value of $36.8 \mathrm{wt} \% \mathrm{ND}_{3}$ (equivalent to $31.2 \mathrm{wt} \% \mathrm{NH}_{3}$ ) stored. This value slightly exceeds the hydrogen equivalent of $5.5 \mathrm{wt} \%$ which corresponds to the DoE goal for $2015 .^{3}$ The hyper-ammoniated phase is stable at room temperature and the complete ammonia release was reached in two main steps, respectively at $350-410 \mathrm{~K}$ and $500-540 \mathrm{~K}$, thus falling in a convenient temperature window, if compared with other known ammonia-storage systems. The comparison between the experimental desorption enthalpies for the two processes and those calculated for the dissociation of the $\mathrm{Li}\left(\mathrm{NH}_{3}\right)_{n}$ clusters $(n$ $=1-2$ ) suggests that the co-intercalation of the Li-ammonia clusters in the fullerene matrix is effective to bring the $\mathrm{Li}-\mathrm{NH}_{3}$ binding energies towards values more suitable for applications in the field of ammonia-storage. 


\section{Acknowledgements}

The authors would like to acknowledge the financial support from the Cariplo foundation (Project number 2013-0592, "Carbon based nanostructures for innovative hydrogen storage systems") and IRSES-EU Project MagNonMag nr. 295180.

\section{References}

1 L. W. Jones, Science, 1971, 174, 367-370.

2 L. Schlapbach and A. Zuttel, Nature, 2001, 414, 353-358.

3 U.S DOE Annual energy outlook, Available online at, http:// www.eia.doe.gov/oiaf/aeo/.

4 A. Klerke, C. H. Christensen, J. K. Norskov and T. Vegge, J. Mater. Chem., 2008, 18, 2304-2310.

5 V. Smil, Nature, 1999, 400, 415.

6 C. H. Christensen, R. Z. Sorensen, T. Johannessen, U. J. Quaade, K. Honkala, T. D. Elmoe, R. Kohler and J. K. Norskov, J. Mater. Chem., 2005, 15, 4106-4108.

7 G. G. M. Fournier, I. W. Cumming and K. Hellgardt, J. Power Sources, 2006, 162, 198-206.

8 J. C. Ganley, F. S. Thomas, E. G. Seebauer and R. I. Masel, Catal. Lett., 2004, 96, 117-122.

9 B. Peng and J. Chen, Energy Environ. Sci., 2008, 1, 479-483.

10 Y. Guo, G. Xia, Y. Zhu, L. Gao and X. Yu, Chem. Commun., 2010, 46, 2599-2601.

11 G. Soloveichik, J.-H. Her, P. W. Stephens, Y. Gao, J. Rijssenbeek, M. Andrus and J. C. Zhao, Inorg. Chem., 2008, 47, 4290-4298.

12 R. Z. Sørensen, J. S. Hummelshøj, A. Klerke, J. B. Reves, T. Vegge, J. K. Nørskov and C. H. Christensen, J. Am. Chem. Soc., 2008, 130, 8660-8668.

13 Z. Huang, J. Gallucci, X. Chen, T. Yisgedu, H. K. Lingam, S. G. Shore and J.-C. Zhao, J. Mater. Chem., 2010, 20, 2743-2745.

14 E. A. Sullivan and S. Johnson, J. Phys. Chem., 1959, 63, 233-238.

15 S. R. Johnson, W. I. F. David, D. M. Royse, M. Sommariva, C. Y. Tang, F. P. A. Fabbiani, M. O. Jones and P. P. Edwards, Chem.-Asian J., 2009, 4, 849-854.

16 C. J. Doonan, D. J. Tranchemontagne, T. G. Glover, J. R. Hunt and O. M. Yaghi, Nat. Chem., 2010, 2, 235-238.

17 J. A. Teprovich, M. S. Wellons, R. Lascola, S.-J. Hwang, P. A. Ward, R. N. Compton and R. Zidan, Nano Lett., 2011, 12, 582-589.

18 P. Mauron, A. Remhof, A. Bliersbach, A. Borgschulte, A. Züttel, D. Sheptyakov, M. Gaboardi, M. Choucair, D. Pontiroli, M. Aramini, A. Gorreri and M. Riccò, Int. J. Hydrogen Energy, 2012, 37, 14307-14314.

19 P. Mauron, M. Gaboardi, A. Remhof, A. Bliersbach, D. Sheptyakov, M. Aramini, G. Vlahopoulou, F. Giglio, D. Pontiroli, M. Riccò and A. Züttel, J. Phys. Chem. C, 2013, 117, 22598-22602.

20 M. Aramini, M. Gaboardi, G. Vlahopoulou, D. Pontiroli, C. Cavallari, C. Milanese and M. Riccò, Carbon, 2014, 67, 92-97.

21 T. Yildirim, O. Zhou, J. E. Fischer, N. Bykovetz, R. A. Strongin, M. A. Cichy, A. B. Smith Iii, C. L. Lin and R. Jelinek, Nature, 1992, 360, 568-571.
22 F. Giglio, D. Pontiroli, M. Gaboardi, M. Aramini, C. Cavallari, M. Brunelli, P. Galinetto, C. Milanese and M. Riccò, Chem. Phys. Lett., 2014, 609, 155-160.

23 M. Gaboardi, C. Cavallari, G. Magnani, D. Pontiroli, S. Rols and M. Riccò, Carbon, 2015, 90, 130-137.

24 M. Gaboardi, S. G. Duyker, C. Milanese, G. Magnani, V. K. Peterson, D. Pontiroli, N. Sharma and M. Riccò, J. Phys. Chem. C, 2015, 119, 19715-19721.

25 M. Aramini, C. Milanese, D. Pontiroli, M. Gaboardi, A. Girella, G. Bertoni and M. Riccò, Int. J. Hydrogen Energy, 2014, 39, 2124-2131.

26 A. K. Douglas, A. T. Joseph Jr, S. Andrew, P. Brent, A. W. Patrick, N. C. Robert and Z. Ragaiy, Nanotechnology, 2013, 24, 455601.

27 M. J. Rosseinsky, D. W. Murphy, R. M. Fleming and O. Zhou, Nature, 1993, 364, 425-427.

28 O. Zhou, R. M. Fleming, D. W. Murphy, M. J. Rosseinsky, A. P. Ramirez, R. B. van Dover and R. C. Haddon, Nature, 1993, 362, 433-435.

29 P. Durand, Y. Dubitsky, M. J. Rosseinsky and A. Zaopo, Dalton Trans., 2004, 3137-3143.

30 M. Riccò, M. Belli, T. Shiroka, D. Pontiroli, M. Pagliari, F. Gianferrari and A. Gorreri, Phys. B, 2006, 374-375, 255258.

31 S. Margadonna, E. Aslanis and K. Prassides, J. Am. Chem. Soc., 2002, 124, 10146-10156.

32 P. Durand, G. R. Darling, Y. Dubitsky, A. Zaopo and M. J. Rosseinsky, Nat. Mater., 2003, 2, 605-610.

33 P. Wzietek, T. Mito, H. Alloul, D. Pontiroli, M. Aramini and M. Riccò, Phys. Rev. Lett., 2014, 112, 066401.

34 A. J. Studer, M. E. Hagen and T. J. Noakes, Phys. B, 2006, 385386, 1013-1015.

35 M. H. Sørby, Y. Nakamura, H. W. Brinks, T. Ichikawa, S. Hino, H. Fujii and B. C. Hauback, J. Alloys Compd., 2007, 428, 297-301.

36 T. E. Salter and A. M. Ellis, Chem. Phys., 2007, 332, 132-138. 37 M. Riccò, T. Shiroka, A. Sartori, F. Bolzoni and M. Tomaselli, EPL, 2001, 53, 762.

38 M. Riccò, G. Fumera, T. Shiroka, O. Ligabue, C. Bucci and F. Bolzoni, Phys. Rev. B: Condens. Matter Mater. Phys., 2003, 68, 035102.

39 T. Shiroka, G. Fumera, O. Ligabue, M. Riccò and G. C. Antonioli, J. Chem. Phys., 2006, 124, 204717.

40 T. E. Salter and A. M. Ellis, J. Phys. Chem. A, 2007, 111, 49224926.

41 W. G. Burgers, Physica, 1934, 1, 561-586.

42 V. A. Nicely and J. L. Dye, J. Chem. Phys., 1970, 52, 4795-4803.

43 M. Trenary, H. F. Schaefer and P. Kollman, J. Am. Chem. Soc., 1977, 99, 3885-3886.

44 R. L. Woodin and J. L. Beauchamp, J. Am. Chem. Soc., 1978, 100, 501-508.

45 J. C. Thompson, Electrons in Liquid Ammonia, Oxford University Press, 1976.

46 W. I. F. David, M. O. Jones, D. H. Gregory, C. M. Jewell, S. R. Johnson, A. Walton and P. P. Edwards, J. Am. Chem. Soc., 2007, 129, 1594-1601. 